\title{
REVIEW | Song Interpretation in 21st Century Pop Music
}

Ralf von Appen, André Doehring, Dietrich Helms

and Allan F. Moore Eds.

Burlington, VT: Ashgate, 2015

ISBN 9781472428004

\section{Sam Vallen}

\section{Griffith University}

samuelvallen@gmail.com

No two listeners hear music the same way. In spite of this, most popular music analysis is undertaken by lone analysts, and accordingly interpreted only through their unique preferences and tastes. The field of "new musicology" has proliferated through tenets of flexibility and interdisciplinarity, but despite its pioneering approach to methodology, a predilection for subjectivity lingers.

Song Interpretation in 21st Century Pop Music offers a counterpoint to this ubiquitous perspective. The book's first half consists of individual analyses; the second half, in contrast, comprises of collaborative analyses undertaken by small groups with varying backgrounds, disciplines, and musical tastes. The substance of Song Interpretation in 21st Century Pop Music was conceived at a musicology summer school in Osnabrück, Germany in 2011, and its two-part structure parallels that of the convention: lecturers presented individual analyses, then students were tasked with group collaborative analyses.

The first half, "Listening Alone", represents the lecturers' individual presentations. In some cases the methods and perspectives utilised are relatively conventional; for instance, Walter Everett's analysis of "I Will Follow You into the Dark" by Death Cab For Cutie examines the harmonic conventions against which audiences subconsciously compare the music they hear; Anne Danielsen's analysis of "Nasty Girl" by Destiny's Child explores the shortcomings of extant 
rhythmic analytical models; and Simon Zagorski-Thomas's analysis of "Sex on Fire" by Kings of Leon considers production choices as major agents of musical meaning. The scope of these three chapters is comparatively narrow, but they are consequently more detailed than the varied analytical approaches surrounding them, providing the summer school's students (and also the reader) a view into the respective approaches through which these three academics have built their celebrity (see Everett 2004; Danielsen 2012; Zagorski-Thomas 2010).

Some musical analyses are expanded through additional analytical contexts, an approach typical of new musicology. André Doehring's study of "New For U" by Andrés also broadly explores Detroit EDM culture, and Dietmar Elflein's analysis of "Pussy" by Rammstein also contextualises it through its GDR background and German signifiers. Allan F. Moore's analysis of Amy Macdonald's "This Is the Life" merges musical analysis with ruminations on listening perspectives and supplementary media (namely its music video and its use in an advertisement), questioning how these media affect readings of the song.

Conversely, some analytical approaches are quite unique. Ralf von Appen's study of Ke\$ha's "Tik Tok" is presented as a fictionalised account of the song's writing and production process. The fictitious dialogue sometimes feels unnatural and stilted, but the process itself is effective in justifying the artistic (or perhaps inartistic) decisions behind the creation of a hit song. Similarly, Dietrich Helms, in perhaps the book's most inventive analytical approach, utilises linguistic theory Jakobson's six functions of communication - to analyse Lady Gaga's "Poker Face", which results in both a unique perspective of the song's communicative processes, and a valuable model for future analysis.

The book's second half, "Listening Together", represents the summer school's collaborative analyses: twenty-six musicologists, grouped and tasked with the analysis of songs chosen for them by the organisers. The first of these collaborative analyses, undertaken by Cláudia Azevedo, Chris Fuller, Juliana Guerrero, Michael Kaler, and Brad Osborn, explores themes of ambiguity and tension in PJ Harvey's "The Words That Maketh Murder". These themes are explored through musical and paramusical characteristics, and are augmented with Lakeoff and Johnson's theories of conceptual metaphor, linking the song's aesthetics to being lost in a swamp. A similar set of varied analytical texts is identified as the agent of communication in "Helplessness Blues" by Fleet Foxes (analysed by Paul Carter, Samantha Englander, Alberto Munarritz, Jadey O'Regan, and Eileen Simonow), but in this case the song's overarching theme is conflict, conveyed through "old versus new" aesthetics and an atypical two-part structure. These two analyses overcome issues of inconsistency by maintaining clear analytical themes foundational to their varied methodologies.

But not all analyses function so thematically coherently. In Janelle Monáe's "Tightrope" (analysed by Frederike Arns, Mark Chilla, Mikko Karjalainen, Esa Lilja, Therea Maierhofer-Lischka, and Matthew Valnes) two themes are identified: referentiality and tension. The former is exhibited in the song's pastiche of past musical styles; the latter is identified in the song's lyrical/narrative meaning (dealing with fame: the metaphorical tightrope). Despite being explored soundly in isolation, these two analytical themes never converge in the analysis, undermining the weight of its findings. 
The remaining two analyses examine different manifestations of thematic duality: how two opposing themes can create greater meaning through contrast and convergence. The first, Félix Eid, María Emelia Greco, Jakub Kasperski, Andrew Martin and Edin Mujkanović's analysis of "Dance Kuduro" by Lucenzo examines how exoticism combined with genre familiarity (dance music's feels and tempos) can result in a hit song. The second, an analysis of Björk's "Crystalline", undertaken by Phil Allcock, Natalia Bieletto, Maxime Cottin, Katharine Nelligan, and Yvonne Thieré, looks at how consistent narrative meaning can exist in a work based on two seemingly contradictory themes: nature and artifice. More than any other of these collaborative studies, this final chapter shows the necessity for intersubjectivity: the group's conclusions were split. Some saw this thematic juxtaposition as a battle between nature and technology, others interpreted it as thematic unification.

The contrasting of individual and group analyses in Song Interpretation in 21st Century Pop Music demonstrates the values of both approaches. On the one hand, the individual analyses are clearly more focussed and refined procedurally, on the other, the group analyses, despite their occasional shortcomings in stylistic and thematic consistency, prove that it is possible for music to be read in the same way it is consumed: intersubjectively, filtered through the tastes and interpretations of many listeners. Despite the incipience of this methodological approach, these group analyses are compelling and convincing.

Popular music has never existed in an experiential vacuum; its mass appeal and the myriad ways it communicates with its audience are the reasons new musicology is, itself, such a varied field. To instil even a semblance of intersubjectivity into popular music analysis seems an undertaking important enough to justify the occasional inconsistency in its execution.

\section{References}

Danielsen, A. 2012. "The Sound of Crossover: Micro-Rhythm and Sonic Pleasure in Michael Jackson's 'Don't Stop 'Til You Get Enough'. Popular Music and Society, 35(2): 151-168.

Everett, W. 2004. "A Royal Scam: The Abstruse and Ironic Bop-Rock Harmony of Steely Dan". Music Theory Spectrum, 26(2): 201-236.

Zagorski-Thomas, S. 2010. "The Stadium in Your Bedroom: Functional Staging, Authenticity and the Audience-Led Aesthetic in Record Production". Popular Music, 29(2): 251-266. 